\title{
Hubungan antara tingkat pendidikan dan status ekonomi dengan kepatuhan perawatan gigi tiruan lepasan
}

\author{
Wiworo Haryani, Dwi Eni Purwati, S. Satrianingsih \\ Poltekkes Kemenkes Yogyakarta, Yogyakarta, Indonesia \\ Jl Tatabumi No 3 Banyuraden, Sleman, Yogyakarta, Indonesia; e-mail: haryaniwiworo@gmail.com
}

Submisi: 7 Mei 2017; Penerimaan: 4 Agustus 2017; Publikasi online: 29 Desember 2017

\begin{abstract}
ABSTRAK
Dalam kesehatan gigi dan mulut terutama untuk menghindari gangguan-gangguan yang dapat terjadi akibat kehilangan gigi tersebut, maka diperlukan penggantian gigi yang hilang dengan gigi tiruan. Kepatuhan perawatan pemakai gigi tiruan lepasan didukung oleh tingkat pendidikan dan status ekonomi. Tujuan penelitian untuk mengetahui hubungan tingkat pendidikan dan status ekonomi dengan kepatuhan perawatan pemakai gigi tiruan lepasan. Metode penelitian ini menggunakan survei observasional dengan rancangan cross sectional. Lokasi penelitian di wilayah kerja Puskesmas Pembantu Tompeyan, Tegalrejo, Yogyakarta. Populasi meliputi seluruh warga yang memenuhi kriteria inklusi yaitu berusia lebih dari 20 tahun dan menggunakan protesa, sudah memiliki penghasilan, bersedia menjadi responden dan bisa bekerja sama. Waktu penelitian pada bulan September sampai dengan November 2016. Teknik pengambilan sampel dengan teknik total sampling dan jumlah sampel ada 43. Instrumen penelitian adalah kuesioner kepatuhan perawatan gigi tiruan berupa checklist 10 pernyataan. Hasil penelitian menunjukkan responden dengan tingkat pendidikan perguruan tinggi memiliki kepatuhan terbesar yaitu 13 orang $(30,2 \%)$ sedangkan responden dengan status ekonomi sedang yang memiliki kepatuhan terbesar yaitu 10 orang (23,3\%). Hasil uji Kendall's Tau menunjukkan ada hubungan yang bermakna antara tingkat pendidikan dengan kepatuhan perawatan pemakai gigi tiruan lepasan $(p=0,049)$ dan status ekonomi dengan kepatuhan perawatan pemakai gigi tiruan lepasan $(p=0,004)$. Kesimpulan penelitian ini adalah ada hubungan antara tingkat pendidikan dan status ekonomi dengan kepatuhan perawatan pemakai gigi tiruan lepasan
\end{abstract}

Kata kunci: kepatuhan perawatan gigi tiruan lepasan; status ekonomi; tingkat pendidikan

\begin{abstract}
The relationship of education and economic status with the obedience of removable dentures care users. In oral health, especially to avoid disturbances which occur due to the loose of tooth, it requires to replace the missing teeth with artificial teeth. The obedience of removable denture care users is supported by the educational level and economic status. The aim of this study is to determine the correlation between education and economic status with the obedience of removable denture care users. This research used an observational survey method with the cross sectional design. The research was conducted in Puskesmas Pembantu Tompeyan (the Branch of Public Healthcare Center) Tegalrejo, Yogyakarta working area. The population covered all residents who met the inclusion criteria in the age of above 20 years old and using protesa, having their own income, willing to be respondents, and able to work together. The research time was from September to November 2016. The sampling technique used a total sampling technique involving 43 samples. The research instrument was the obedience of removable denture care users questionnaire in the form of 10 statement checklists. The results of the research showed 13 respondents with college education level who had the greatest obedience (30.2\%), while 10 respondents with middle economic status had the biggest obedience (23.3\%). According to Kendall's Tau test results, this research had a significant relationship between the educational level and the obedience of removable denture care users; $(p=0.049)$ and between economic status and the obedience of removable denture care users; $(p=0.004)$. It can be concluded that there is a relationship between the educational level and economic status with the removable denture care users' obedience
\end{abstract}

Keywords: obedience of denture removable dentures care users; economic status; educational level

\section{PENDAHULUAN}

Tingkat pendidikan berpengaruh terhadap perubahan sikap dan perilaku hidup sehat. Tingkat pendidikan yang lebih tinggi akan memudahkan seseorang atau masyarakat untuk menyerap informasi dan mengimplementasikannya dalam perilaku dan gaya hidup sehari-hari, khususnya dalam hal kesehatan. ${ }^{1}$ Kesehatan gigi dan mulut merupakan bagian dari kesehatan tubuh yang tidak dapat dipisahkan antara satu dengan yang lainnya, sebab kesehatan gigi dan mulutakan mempengaruhi kesehatan tubuh keseluruhannya. Kehilangan 
gigi dapat mengakibatkan gangguan pada fungsi pengunyahan, fungsi Temporo-mandibular Joint (TMJ), dan psikologis yaitu estetika dan fungsi bicara. Kebersihan rongga mulut pemakai gigi tiruan lepasan harus tetap diperhatikan, karena kebersihan gigi tiruan dapat mendukung kesehatan rongga mulut secara menyeluruh. Gigi tiruan harus dijaga sebersih mungkin untuk mencegah kehilangan gigi lebih lanjut, radang gingiva, infeksi bakteri dan jamur, serta agar gigi tiruan tersebut tidak berbau. ${ }^{2}$

Berdasarkan pada Undang-Undang RI No 20 Tahun 2003 tentang Sistem Pendidikan Nasional menyebutkan bahwa pendidikan adalah usaha sadar dan terencana untuk mewujudkan suasana belajar dan proses pembelajaran agar peserta didik secara aktif mengembangkan potensi dirinya untuk memiliki kekuatan, spiritual keagamaan, pengendalian diri, kepribadian, kecerdasan, akhlak mulia serta keterampilan, yang diperlukan dirinya, masyarakat, bangsa dan negara. Pendidikan dasar merupakan jenjang pendidikan yang melandasi pendidikan menengah. Pendidikan dasar berbentuk Sekolah Dasar (SD) dan Madrasah Ibtidaiyah (MI) dan bentuk lain yang sederajat serta Sekolah Menengah Pertama (SMP) dan Madrasah Tsanawiyah (MTs) atau bentuk lain yang sederajat. Pendidikan menengah merupakan lanjutan pendidikan dasar. Pendidikan Menengah terdiri atas pendidikan menengah umum dan pendidikan menengah kejuruan. Pendidikan menengah berbentuk Sekolah Menengah Atas (SMA), Madrasah Aliyah (MA), Sekolah Menengah Kejuruan (SMK) atau bentuk lain yang sederajat. Pendidikan Tinggi (PT) merupakan lanjutan jenjang pendidikan menengah yang mencakup program pendidikan diploma, sarjana, magister, spesialis, doktor, yang diselenggarakan oleh perguruan tinggi. $^{3}$

Tingkat ekonomi seseorang berhubungan erat dengan berbagai masalah kesehatan. Orang dengan tingkat ekonomi rendah akan lebih berkonsentrasi terhadap pemenuhan kebutuhan dasar yang menunjang kehidupannya dan kehidupan keluarganya, sebaliknya orang dengan tingkat ekonomitinggi akan mempunyai kesempatan lebih besar dalam menempuh pendidikan. Orang dengan tingkat ekonomi tinggi akan lebih mudah menerima informasi sehingga makin banyak pula pengetahuan yang dimiliki, hal ini berdampak pada perhatian terhadap kesehatan diri dan keluarga. ${ }^{4}$ Status ekonomi memberi dampak pada pemenuhan kebutuhan primer, sekunder dan tersier keluarga. Semakin tinggi status ekonomi, seseorang semakin mampu memenuhi kebutuhan hidupnya termasuk memilih bentuk pelayanan kesehatan yang berkualitas. ${ }^{5}$ Status ekonomi juga mempengaruhi kondisi kesehatan mulut seseorang, sebagai salah satu faktor yang berpengaruh dalam menciptakan permintaan perawatan gigi, serta merupakan sarana kemampuan dalam pemeliharaan kesehatan gigi dan mulut. ${ }^{6}$

Seseorang kehilangan gigi dan datang ke dokter gigi sebetulnya ada tiga pilihan yang dapat dilakukan seperti tidak melakukan penggantian pada gigi yang hilang, melakukan pemasangan gigi tiruan dan melakukan gigi pengganti gigi geligi sebagian lepasan. ${ }^{7}$ Pemakaian gigi tiruan digunakan untuk mengganti gigi yang hilang supaya tidak mengganggu fungsi pengunyahan, estetika, dan pengucapan, namun demikian tidak semua orang memakai gigi tiruan. Alasan tidak menggunakan gigi tiruan antara lain tingkat pendidikan dan status sosial ekonomi yang rendah, maupun kurangnya ketersediaan pelayanan kesehatan gigi dan mulut. ${ }^{8}$

Puskesmas Tegalrejo, terletak di Kecamatan Tegalrejo, merupakan fasilitas kesehatan yang memiliki wilayah kerja meliputi 4 (empat) kelurahan yaitu Kricak, Karangwaru, Tegalrejo, dan Bener. Wilayah kerja Puskesmas Pembantu Tompeyan meliputi 4 (empat) kelurahan, berpusat di Desa Tompeyan. Berdasarkan studi pendahuluan yang telah dilakukan melalui metode wawancara, penduduk di wilayah kerja Puskesmas Pembantu Tompeyan dari 7 orang sebanyak 5 orang $(71,4 \%)$ diantaranya menggunakan gigi tiruan lepasan. Pemakai gigi tiruan tersebut memiliki alasan yang mendorong untuk memakai gigi tiruan, baik dari segi estetika, kegunaan ataupun kebutuhan. Tingkat pendidikan dan status ekonomi merupakan beberapa hal yang menjadi pertimbangan utama seseorang menggunakan gigi tiruan lepasan. Kepatuhan perawatan merupakan 
tingkat perilaku dalam melaksanakan cara perawatan, pengobatan, dan perilaku yang disarankan tenaga kesehatan. Kesadaran akan kepatuhan terhadap perawatan gigi tiruan lepasan juga dapat dipengaruhi oleh tingkat pendidikan seseorang dan status ekonominya, oleh karena itu penulis tertarik untuk melakukan penelitian tentang kepatuhan perawatan pemakai gigi tiruan lepasan yang dihubungkan dengan tingkat pendidikan dan status ekonomi. Tujuan penelitian ini untuk mengetahui hubungan antara tingkat pendidikan dan status ekonomi dengan kepatuhan perawatan pemakai gigi tiruan lepasan di wilayah kerja Puskesmas Pembantu Tompeyan, Tegalrejo, Yogyakarta.

\section{METODE PENELITIAN}

Jenis penelitian ini adalah survei observasional menggunakan rancangan cross sectional. Tingkat pendidikan dan status ekonomi merupakan variabel pengaruh sedangkan kepatuhan perawatan pemakai gigi tiruan lepasan merupakan variabel terpengaruh. ${ }^{9}$ Penelitian dilakukan pada bulan September sampai dengan November 2016 di wilayah kerja Puskesmas Pembantu Tompeyan, Tegalrejo, Yogyakarta.

Instrumen penelitian ini adalah kuesioner berbentuk check list dengan 10 pernyataan tentang kepatuhan perawatan gigi tiruan lepasan. Data diperoleh dengan cara melihat skor yang diperoleh dari masing-masing responden. Pengukuran tingkat pendidikan menggunakan kuesioner yang dinyatakan dengan skala ordinal meliputi Sekolah Dasar (SD), Sekolah Menengah Pertama (SMP), Sekolah Menengah Atas (SMA) dan Akademi atau Perguruan Tinggi (PT). ${ }^{3}$ Pengukuran status ekonomi menggunakan kuesioner dan dinyatakan dalam skala ordinal, yaitu penghasilan perbulan dengan kriteria rendah (< Rp1.499.999), sedang (Rp1.500.000 - Rp2.499.999), tinggi (Rp2.500.000 - Rp3.499.999), sangat tinggi (> Rp3.500.000). ${ }^{10}$ Penelitian ini menggunakan bentuk pertanyaan tertutup dengan tipe dichotomous choice, hanya disediakan dua jawaban/ alternatif dan responden hanya memilih satu diantaranya "Ya" atau "Tidak" dengan skor 1 jika memilih jawaban "Ya" dan skor 0 jika memilih jawaban "Tidak". ${ }^{11}$
Pengukuran kepatuhan terhadap perawatan pemakai gigi tiruan lepasan, diperoleh dari skor masing - masing responden dengan ketentuan apabila responden melakukan $\geq 5$ jenis perawatan maka responden tersebut patuh pada perawatan gigi tiruan lepasan, sedangkan apabila responden melakukan $<5$ jenis perawatan maka responden tersebut tidak patuh pada perawatan gigi tiruan lepasan. Nilai kepatuhan ini ditetapkan peneliti berdasarkan jawaban responden pada kuesioner. Kuesioner berisi 10 item pernyataan sesuai standar perawatan yang perlu dilakukan oleh pemakai gigi tiruan lepasan yang meliputi membersihkan gigi tiruan lepasan dua kali sehari, melepas dan merendam gigi tiruan lepasan ketika tidur, merendam gigi tiru lepasan dengan air, menggosok gigi tiruan lepasan menggunakan sikat halus, membilas gigi tiruan lepasan sebelum dipakai setelah direndam, memakai perekat gigi tiruan lepasan, mengganti gigi tiruan lepasan setiap 5 tahun sekali, memeriksa gusi sebelum memakai gigi tiruan lepasan, dan menghubungi dokter ketika gigi tiruan lepasan rusak. ${ }^{12}$

Populasi mencakup seluruh warga di wilayah kerja Puskesmas Pembantu Tompeyan Yogyakarta yang memenuhi kriteria inklusi yaitu orang yang menggunakan gigi tiruan lepasan, usia $>20$ tahun, sudah memiliki penghasilan, bersedia menjadi responden penelitian, dan bisa bekerja sama. Teknik pengambilan sampel adalah teknik sampel jenuh, diperoleh jumlah sampel sebanyak 43 orang. Data hasil penelitian dianalisis menggunakan uji korelasi Kendall's Tau. ${ }^{13}$ Penelitian ini sudah dinyatakan layak etik oleh Komisi Etik Penelitian Kesehatan Poltekkes Kemenkes Yogyakarta NO.LB.01.01/KE/ LIV/479/2016.

\section{HASIL PENELITIAN}

Hasil penelitian menunjukkan bahwa sebagian besar responden pemakai gigi tiruan lepasan adalah perempuan ( $n=31$ orang; $72,1 \%$ ); kelompok umur 23-43 tahun ( $n=23$ orang; $53,5 \%$ ); berpendidikan SMA ( $n=18$ orang; $41,9 \%$ ); status ekonomi sedang (Rp1.500.000 - Rp2.499.999) sebanyak 15 orang $(34,9 \%)$. Responden yang patuh terhadap perawatan ada 25 orang $(58,1 \%)$ (Tabel 1$)$. 
Tabel 1. Distribusi frekuensi responden berdasarkan jenis kelamin, umur, tingkat pendidikan, status ekonomi, dan kepatuhan perawatan di Wilayah Kerja Puskesmas Pembantu Tompeyan Yogyakarta $(n=43$ orang)

\begin{tabular}{|c|c|c|}
\hline Variabel & $\mathbf{n}$ & Persentase (\%) \\
\hline Jenis Kelamin & 12 & 27,9 \\
\hline Perempuan & 31 & 72,1 \\
\hline Jumlah & 43 & 100 \\
\hline \multicolumn{3}{|l|}{ Umur } \\
\hline $23-43$ tahun & 23 & 53,5 \\
\hline $44-64$ tahun & 20 & 46,5 \\
\hline Jumlah & 43 & 100 \\
\hline \multicolumn{3}{|l|}{ Tingkat pendidikan } \\
\hline Sekolah Dasar (SD) & 2 & 4,7 \\
\hline Sekolah Menengah Pertama (SMP) & 7 & 16,3 \\
\hline Sekolah Menengah Atas (SMA) & 18 & 41,9 \\
\hline Akademi/Perguruan Tinggi (PT) & 16 & 37,2 \\
\hline Jumlah & 43 & 100 \\
\hline \multicolumn{3}{|l|}{ Status ekonomi } \\
\hline Rendah (<Rp1.499.999) & 11 & 25,6 \\
\hline Sedang (Rp1.500.000 - Rp2.499.999) & 15 & 34,9 \\
\hline Tinggi (Rp2.500.000 - Rp3.499.999) & 10 & 23,3 \\
\hline Sangat Tinggi (>Rp3.500.000) & 7 & 16,3 \\
\hline Jumlah & 43 & 100 \\
\hline \multicolumn{3}{|l|}{ Kepatuhan perawatan } \\
\hline Patuh & 25 & 58,1 \\
\hline Tidak Patuh & 18 & 41,9 \\
\hline Jumlah & 43 & 100 \\
\hline
\end{tabular}

Tabel 2. Tabulasi silang berdasarkan tingkat pendidikan dan status ekonomi dengan kepatuhan perawatan pemakai gigi tiruan lepasan di Wilayah Kerja Puskesmas Pembantu Tompeyan Yogyakarta ( $\mathrm{n}=43$ orang)

\begin{tabular}{|c|c|c|c|c|c|c|c|}
\hline \multirow{4}{*}{ Variabel } & \multicolumn{6}{|c|}{ Kepatuhan Perawatan Pemakai Gigi } & \multirow[t]{4}{*}{$p$} \\
\hline & & Tirc & & & \multirow{2}{*}{\multicolumn{2}{|c|}{ Total }} & \\
\hline & \multicolumn{2}{|c|}{ Patuh } & \multicolumn{2}{|c|}{ Tidak Patuh } & & & \\
\hline & $\mathrm{n}$ & $\%$ & $\mathrm{n}$ & $\%$ & Jumlah & $\%$ & \\
\hline \multicolumn{8}{|l|}{ Tingkat pendidikan } \\
\hline Sekolah Dasar (SD) & 2 & 4,7 & 0 & 0 & 2 & 4,7 & 0,049 \\
\hline Sekolah Menengah Pertama (SMP) & 2 & 4,7 & 5 & 11,6 & 7 & 16,3 & \\
\hline Sekolah Menengah Atas (SMA) & 8 & 18,6 & 10 & 23,3 & 18 & 41,9 & \\
\hline Akademi / Perguruan Tinggi (PT) & 13 & 30,2 & 3 & 7 & 16 & 37,2 & \\
\hline Jumlah & 25 & 58,1 & 18 & 41,9 & 43 & 100 & \\
\hline \multicolumn{8}{|l|}{ Status ekonomi } \\
\hline Rendah (<Rp1.499.999) & 2 & 2,7 & 9 & 20,9 & 11 & 25,6 & 0,004 \\
\hline Sedang (Rp1.500.000 - Rp2.499.999) & 10 & 23,3 & 5 & 11,6 & 15 & 34,9 & \\
\hline Tinggi (Rp2.500.000 - Rp3.499.999) & 7 & 16,3 & 3 & 7 & 10 & 23,3 & \\
\hline Sangat Tinggi (>Rp3.500.000) & 6 & 14 & 1 & 2,3 & 7 & 16,3 & \\
\hline Jumlah & 25 & 58,1 & 18 & 41,9 & 43 & 100 & \\
\hline
\end{tabular}

Keterangan:

Uji korelasi Kendall's tau, * signifikan jika p<0,05

Responden dengan tingkat pendidikan SMA ( $n=18$ orang; $41,9 \%$ ) yang patuh terhadap perawatan gigi tiruan lepasan adalah 8 orang $(18,6 \%)$. Responden dengan tingkat pendidikan SD memiliki jumlah terkecil ( $n=2$ orang; $4,7 \%$ ). Seluruh responden SD patuh terhadap perawatan gigi tiruan lepasan (Tabel 2). Sebagian besar responden berstatus ekonomi sedang ( $n=15$ orang; $34,9 \%$ ).
Responden status ekonomi sedang yang patuh terhadap perawatan gigi tiruan lepasan sebanyak 10 orang $(23,3 \%)$; tidak patuh sebanyak 5 orang $(11,5 \%)$. Responden dengan jumlah terkecil adalah responden dengan status ekonomi sangat tinggi yaitu 7 orang (16,3\%). Responden status ekonomi tinggi yang patuh terhadap perawatan gigi tiruan lepasan sebanyak 6 orang (14\%); tidak patuh 
sebanyak 1 orang (2,3\%) Uji korelasi Kendall's Tau menunjukkan bahwa terdapat korelasi yang signifikan antara tingkat pendidikan $(p=0,049)$ dan status ekonomi $(p=0,004)$ dengan kepatuhan perawatan (Tabel 2).

\section{PEMBAHASAN}

Distribusi frekuensi responden penelitian berdasarkan jenis kelamin menunjukkan jumlah responden laki - laki sebanyak 12 orang $(27,9 \%)$ sedangkan jumlah responden perempuan sebanyak 31 orang $(72,1 \%)$. Hasil penelitian ini sama dengan yang dilakukan oleh Agtini yang menunjukkan bahwa pemakai gigi tiruan perempuan lebih banyak dibandingkan dengan laki - laki. ${ }^{14}$ Hasil penelitian yang dilakukan oleh American Dental Association melaporkan bahwa resiko perempuan mengalami penyakit mulut lebih banyak dikarenakan perempuan pada umumnya mengalami kondisi menstruasi, kehamilan dan menopouse dimana pada saat itu hormon estrogen meningkat disertai dengan penurunan penyerpan kalsium yang meningkatkan kerapuhan gigi dan perdangan sehingga persentase kehilangan gigi pada perempuan lebih tinggi. ${ }^{15}$

Karakteristik responden berdasarkan tingkat pendidikan meliputi SD, SMP, SMA dan Akademi atau PT. Frekuensi tertinggi pemakaian gigi tiruan adalah responden dengan tingkat pendidikan lulusan SMA sebesar 18 orang (41,9\%). Frekuensi responden yang memiliki tingkat pendidikan Akademi/PT hampir sama dengan frekuensi responden yang memiliki tingkat pendidikan SMA yaitu 16 orang $(37,2 \%)$. Tingkat pendidikan Akademi/PT memiliki kepatuhan tertinggi yaitu 13 orang $(30,2 \%)$. Hal ini menggambarkan bahwa semakin tinggi tingkat pendidikan maka semakin besar pula persentase responden yang patuh terhadap perawatan gigi tiruan lepasan. Notoatmodjo mengatakan tingkat pendidikan sangat berpengaruh terhadap perubahan sikap dan perilaku hidup sehat. ${ }^{9}$

Frekuensi responden tertinggi pada kategori status ekonomi sedang (Rp1.500.000 Rp2.499.999) yaitu 15 orang (34,9\%), frekuensi kepatuhan tertinggi pada kategori status ekonomi sedang yaitu 10 orang $(23,3 \%)$. Status ekonomi merupakan kemampuan finansial untuk memenuhi segala kebutuhan hidup dan bisa digunakan untuk membiayai semua program pengobatan dan perawatan. Status ekonomi seseorang berhubungan erat dengan berbagai masalah kesehatan, termasuk kesehatan gigi dan mulut. Status ekonomi merupakan sarana kemampuan dalam pemeliharaan kesehatan gigi dan mulut. ${ }^{6}$ Penelitian lain menunjukkan bahwa ada hubungan yang signifikan antara status sosial ekonomi dengan kebutuhan pemakaian gigi tiruan. ${ }^{16}$

Hasil tabulasi silang antara tingkat pendidikan dengan kepatuhan perawatan pemakai gigi tiruan lepasan menunjukkan bahwa responden dengan tingkat pendidikan Akademi/PT memiliki kepatuhan perawatan terbanyak yaitu 13 orang $(30,2 \%)$. Hasil yang didapatkan serupa dengan penelitian yang dilakukan oleh Deli bahwa tingkat pendidikan memiliki hubungan dan berpengaruh pada kepatuhan pasien. ${ }^{17} \mathrm{Hal}$ ini didukung juga oleh Prijadarminto bahwa kepatuhan adalah suatu kondisi yang tercipta dan berbentuk melalui proses dari serangkaian perilaku yang menunjukkan nilai-nilai ketaatan, kepatuhan, kesetiaan, keteraturan dan ketertiban. ${ }^{18}$ Penelitian Murakami dkk menemukan bahwa pendidikan orang tua mempunyai hubungan yang signifikan terkait dengan kesehatan mulut anak. ${ }^{19}$

Hasil tabulasi silang antara status ekonomi dengan kepatuhan perawatan pemakai gigi tiruan lepasan menunjukkan bahwa responden dengan status ekonomi sedang memiliki kepatuhan perawatan terbanyak yaitu 10 orang $(23,3 \%)$. Hasil penelitian ini didukung oleh pendapat Tulangow dkk yang mengatakan bahwa status ekonomi merupakan salah satu faktor yang mempengaruhi status kesehatan, oleh karena untuk memenuhi kebutuhan hidup dan mendapatkan tempat pelayanan kesehatan yang diinginkan lebih memungkinkan bagi kelompok sosial ekonomi tinggi dibandingkan dengan kelompok sosial ekonomi rendah. ${ }^{20} \mathrm{Hal}$ ini didukung pula oleh beberapa penelitian epidemiologi tentang ketidakseimbangan status sosial ekonomi dalam kesehatan mulut menunjukkan bahwa kelompok sosial ekonomi 
yang lebih rendah cenderung memiliki kesehatan mulut yang buruk daripada yang lebih tinggi. ${ }^{21}$

Hasil uji korelasi Kendall's Tau menunjukkan hubungan tingkat pendidikan dan status ekonomi dengan kepatuhan perawatan pemakai gigi tiruan lepasan yaitu ada hubungan antara tingkat pendidikan dengan kepatuhan perawatan memiliki nilai signifikasi $p=0,049$. Ada hubungan status ekonomi dengan kepatuhan perawatan pemakai gigi tiruan lepasan memiliki nilai signifikasi $p=0,004$. Hasil yang didapatkan serupa dengan penelitian yang dilakukan oleh Fisyahri bahwa tingkat pendidikan dan status ekonomi memiliki hubungan dengan perilaku seseorang dalam menggunakan gigi tiruan. ${ }^{22}$ Hilangnya gigi tanpa penggantian dengan gigi tiruan mengakibatkan hilangnya fungi mulut yang parah. Kondisi ini biasa terjadi pada populasi miskin baik di negara maju dan negara berkembang. ${ }^{23}$ Tingkat pendidikan merupakan salah satu faktor yang kuat dalam mempengaruhi kepatuhan perawatan pemakai gigi tiruan lepasan di wilayah kerja Puskesmas Pembantu Tompeyan, Tegalrejo, Yogyakarta, hal ini sesuai dengan Notoatmodjo bahwa pengetahuan sangat erat kaitannya dengan tingkat pendidikan, diharapkan seseorang dengan tingkat pendidikan tinggi yang dimilikinya, maka pengetahuannya akan semakin luas. ${ }^{9}$

\section{KESIMPULAN}

Terdapat hubungan signifikan antara tingkat pendidikan dan status ekonomi dengan kepatuhan perawatan pemakai gigi tiruan lepasan pada masyarakat di wilayah kerja Puskesmas Pembantu Tompeyan, Tegalrejo, Yogyakarta. Berdasarkan penelitian ini, saran yang diajukan adalah perlu adanya penelitian lebih lanjut dengan menggunakan faktor-faktor yang lebih spesifik, misalnya tradisi/ budaya lokal, kebiasaan mengunyah, dan sebagainya. Bagi petugas kesehatan disarankan untuk melakukan sosialisasi kepada masyarakat mengenai instruksi perawatan yang harus dilakukan pada pemakai gigi tiruan lepasan. Bagi masyarakat disarankan untuk lebih peduli dan menyadari pentingnya pemeliharaan gigi tiruan lepasan sehingga terjaga kesehatan gigi dan mulutnya.

\section{DAFTAR PUSTAKA}

1. Herijulianti E, Indriani SE, Artini S. Pendidikan kesehatan gigi. Jakarta: EGC; 2002.

2. Muluwere VO, Mariati NW, Wicaksono DA. Gambaran pengetahuan dan status kebersihan mulut pada pemakai gigi truan sebagian lepasan di Kecamatan Batu Kota Malalayang. J e-Gigi. 2015; 3(1): 197 - 202.

3. Undang-Undang Republik Indonesia No 20 Tahun 2003 mengenai Sistem Pendidikan Nasional.

4. Moreira RS, Nico LS, Tomita NERL. Oral health of brazilian elderly: a systematic review of epidemiologic status and dental care access. Rep Public Heal. 2015; 21(16): $65-75$.

5. Budiharto. Pengantar ilmu perilaku kesehatan dan pendidikan kesehatan gigi. Jakarta: EGC; 2008.

6. Harini S. Pengaruh tingkat pendidikan dan sosial ekonomi dengan kebutuhan pemakaian gigi tiruan sebagian lepasan. Skripsi, Fakultas Kedokteran, Universitas Gadjah Mada; 2005.

7. Gunadi HA. Buku ajar geligi tiruan sebagian lepasan jilid 2. Jakarta: Hipocrates.

8. Moreira RdeS, Nico LS, Tomita NE. Oral health conditions among the elderly in Southeastern Sao Paulo State. J Appl Oral Sci. 2009; 17(3): $170-178$.

9. Notoatmodjo S. Pendidikan dan perilaku kesehatan. Jakarta: Rineka Cipta; 2003.

10. Badan Pusat Statistik. Gini Ratio Kota Yogyakarta. Yogyakarta: BPS; 2011.

11. Notoatmodjo S. Metodologi penelitian kesehatan. Jakarta: Rineka Cipta; 2012. $27-41$.

12. Rahmadhan AG. Serba-Serbi kesehatan gigi dan mulut. Jakarta: Bukune; 2010. 86 - 90.

13. Sugiyono. Metode penelitian pendidikan. Bandung: Alfabeta; 2010.

14. Agtini MD. Persentase pengguna protesa di Indonesia. Media Litbang Kesehat. 2010; XX(2): 50 - 58. 
15. Jatuadomi, Gunawan PN, Siagian KV. Alasan pemakaian gigi tiruan lepasan pada pasien poliklinik gigi di BLU RSUP Prof. Dr. R. D. Kandou Manado. J e-Gigi. 2016; 4(1): 2 - 7.

16. Pessoa DMdaV, Roncalli AG, Lima KCDe. Economic and sociodemographic inequalities in complete denture need among older Brazilian adults : a cross-sectional populationbased study. BMC Oral Health. 2017; 17(5): 1 - 8. doi:10.1186/s12903-016-0233-9.

17. Deli WLV. Tingkat pendidikan dan status ekonomi dengan kepatuhan pasien perawatan pulpektomi di klinik dentes yogyakarta. 2013. $30-40$.

18. Prijadarminto. Kepatuhan sebagai perilaku. Jakarta: Bina Pustaka; 2003.

19. Murakami K, Kondo N, Ohkubo T, Hashimoto $H$. The effect of fathers' and mothers' educational level on adult oral health in Japan. Community Dent Oral Epidemiol. 2016; 44(3): $283-291$.
20. Tulangow JT, Mariati NW, Mintjelungan C. Gambaran status karies murid Sekolah Dasar Negeri 48 Manado berdasarkan status sosial ekonomi orang tua. J e-Gigi. 2013; 1(2): $85-93$.

21. Petersen PE, Kwan S. Equity, social determinants and public healt programmes the case of oral health. Community Dent Oral Epidemiol. 2011; 39(6): 481 - 487.

22. Fisyahri AN. Tingkat pendidikan dan status ekonomi dengan minat menggunakan gigi tiruan sebagian lepasan pada pra lansia. Skripsi. Poltekkes Kemenkes Yogyakarta; 2013. 32 - 41.

23. Petersen PE, Kandelman D, Arpin S, Ogawa $\mathrm{H}$. Global oral health of older people - Call for public health action. Community Dent Health. 2010; 25(2): 257 - 268. doi:10.1922/CDH. 